\title{
European Headache Federation recommendations for neurologists managing giant cell arteritis
}

\author{
S. P. Mollan ${ }^{1}$ (D) K. Paemeleire ${ }^{2}$, J. Versijpt ${ }^{3}$, R. Luqmani ${ }^{4}$ and A. J. Sinclair ${ }^{5,6,7^{*}}$ (D)
}

\begin{abstract}
Background and aim: Giant cell arteritis (GCA) remains a medical emergency because of the risk of sudden irreversible sight loss and rarely stroke along with other complications. Because headache is one of the cardinal symptoms of cranial GCA, neurologists need to be up to date with the advances in investigation and management of this condition. The aim of this document by the European Headache Federation (EHF) is to provide an evidence-based and expert-based recommendations on GCA.

Methods: The working group identified relevant questions, performed systematic literature review and assessed the quality of available evidence, and wrote recommendations. Where there was not a high level of evidence, the multidisciplinary (neurology, ophthalmology and rheumatology) group recommended best practice based on their clinical experience.

Results: Across Europe, fast track pathways and the utility of advanced imaging techniques are helping to reduce diagnostic delay and uncertainty, with improved clinical outcomes for patients. GCA is treated with high dose glucocorticoids (GC) as a first line agent however long-term GC toxicity is one of the key concerns for clinicians and patients. The first phase 2 and phase 3 randomised controlled trials of Tocilizumab, an IL-6 receptor antagonist, have been published. It is now been approved as the first ever licensed drug to be used in GCA.
\end{abstract}

Conclusion: The present article will outline recent advances made in the diagnosis and management of GCA.

Keywords: Giant cell arteritis, Temporal arteritis, Headache, Large vessel Vasculitis, Polymyalgia Rheumatica, Tocilizumab, Vision, Anterior Ischaemic optic neuropathy, Stroke

\section{Objective}

To systematically review the literature for advances in the diagnosis and management of Giant cell arteritis (GCA), in order to provide practical guidance statements for the neurologist (which concords with and complements guidelines from other specialties).

\footnotetext{
* Correspondence: a.b.sinclair@bham.ac.uk

${ }^{5}$ Metabolic Neurology, Institute of Metabolism and Systems Research, University of Birmingham, Edgbaston, Birmingham B15 2TT, UK

${ }^{6}$ Department of Neurology, University Hospitals Birmingham, Queen Elizabeth Hospital, Birmingham, UK

Full list of author information is available at the end of the article
}

\section{Methods}

The European Headache Federation (EHF) board identified GCA as a disease area where new evidence has emerged. The working group was put together to include neurologists with a specialist interest in headache and an ophthalmologist. The group identified relevant questions then performed a systematic literature review. The literature search included all English papers on PubMed between inception of the database until July 1st, 2019, a further search was performed on January 17th, 2020 to ensure all relevant papers could be

(c) The Author(s). 2020 Open Access This article is licensed under a Creative Commons Attribution 4.0 International License, which permits use, sharing, adaptation, distribution and reproduction in any medium or format, as long as you give appropriate credit to the original author(s) and the source, provide a link to the Creative Commons licence, and indicate if changes were made. The images or other third party material in this article are included in the article's Creative Commons licence, unless indicated otherwise in a credit line to the material. If material is not included in the article's Creative Commons licence and your intended use is not permitted by statutory regulation or exceeds the permitted use, you will need to obtain permission directly from the copyright holder. To view a copy of this licence, visit http://creativecommons.org/licenses/by/4.0/ The Creative Commons Public Domain Dedication waiver (http://creativecommons.org/publicdomain/zero/1.0/) applies to the data made available in this article, unless otherwise stated in a credit line to the data. 
included. The papers were assessed for their quality and the recommendations drafted. The draft recommendations were critically reviewed by a rheumatologist, who became part of the EHF GCA panel. The final document was reviewed and approved by all members of the panel. Where there was not a high level of evidence, the multidisciplinary EHF GCA panel recommended best practice based on their clinical experience and that of other specialty guideline groups.

\section{Background}

GCA is the cause of a critical secondary headache, that if left undiagnosed has serious permanent consequences for the patient [1]. It is the commonest form of systemic granulomatous vasculitis [2] and the immunopathophysiology is well described $[3,4]$. It is likely that both genetics and environmental factors are important in initiating the inflammatory cascade $[5,6]$.

The incidence of GCA is between 15 to 25 cases per 100,000 persons over 50 years of age, and increases with age [7]. It more commonly affects women with a lifetime risk of GCA in women of $1 \%$ compared to $0.5 \%$ in men [8]. It is a disease of Caucasians and has a higher incidence in Scandinavian countries and in populations of Northern European descent [9].

Due to the risk of sudden permanent sight loss in between 8 and $30 \%[10,11]$, and stroke in between 3 and $10 \%$ [12], GCA is a medical emergency. GCA is classified as a large vessel vasculitis (LVV) as defined by the Chapel Hill Consensus Definitions because it affects the aorta and its major branches; however, any size artery may be affected, such as small ocular and periocular arteries that lead to visual loss [2]. It is now known to be a spectrum of phenotypically overlapping conditions including cranial GCA (previously known as temporal arteritis), and extra-cranial GCA otherwise termed large
vessel-GCA (LV-GCA), usually involving the aorta and its larger supra-aortic branches, and polymyalgia rheumatica (PMR) [13]. However, any individual patient may have an overlap of more than one subtype (case vignette 1, Fig. 1). The most commonly affected cranial arteries are the temporal, ophthalmic, and posterior ciliary arteries causing visual loss, and rarely the vertebral or carotid territories that can lead to stroke [14].

Clinically it can be difficult to diagnose, because the symptoms can be insidious $[15,16]$. Evidence suggests that increasing numbers of patients are being investigated for suspected GCA [17]. Across Europe, rheumatology centres have set up rapid access investigation pathways, resulting in improved outcomes for patients [18]. Advancing imaging techniques have demonstrated a larger portion of patients with large vessel involvement both with auxiliary ultrasound [19] and formal large vessel imaging studies [20]. In management of the disease, we now acknowledge that many patients with GCA are exposed to high cumulative doses of glucocorticoids (GC), resulting in significant increasing long-term [21]. The first ever therapy, Tocilizumab, that is specifically licensed for GCA and may be used as a GC-sparing agent, was given regulatory approval in 2017. GCA is moving from a condition managed by many specialists to a disease requiring expertise in both the diagnosis and longterm management of the condition.

This timely guidance for neurologists is based on the formation of questions to allow systematic interrogation of the current literature. The two main themes include diagnosis and treatment of GCA.

What are the characteristics of headache in GCA? The International Headache Society (IHS) definition of headache attributable to GCA requires two of the following to be fulfilled in any new headache:

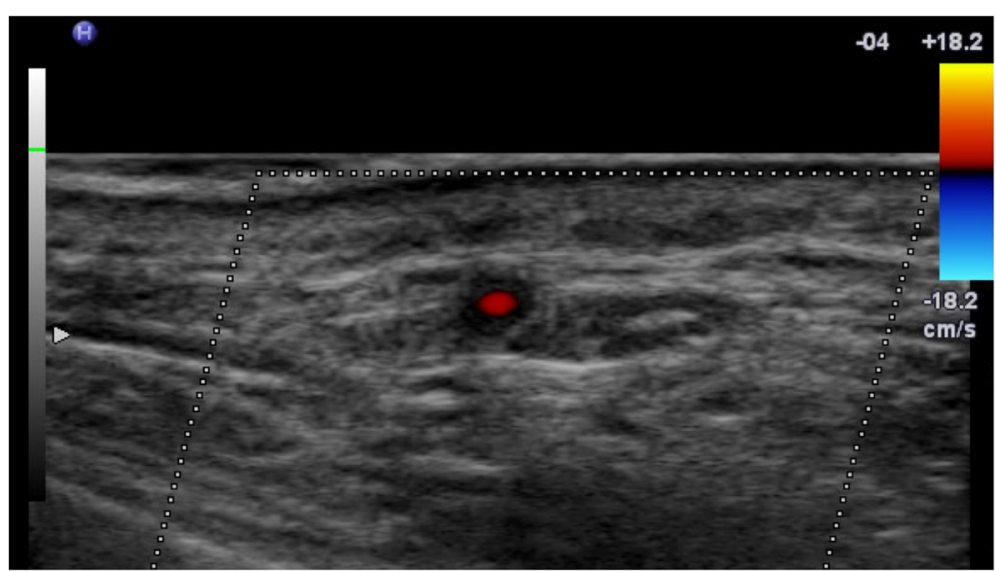

Fig. 1 CDUS of the right temporal artery with a hyporeflective « halo » around the temporal artery in a patient with subsequently a positive temporal artery biopsy 
1. headache has developed in temporal relation to other symptoms and/or clinical or biological signs of onset of GCA, or has led to the diagnosis of GCA

2. either or both of the following:

- a) headache has significantly worsened in parallel with worsening of GCA

- b) headache has significantly improved or resolved within 3 days of high-dose steroid treatment

3. headache is associated with scalp tenderness and/or jaw claudication [22].

The IHS comment that the variability in the headache and other symptoms of GCA are such that any recent persisting headache in a patient over 60 years of age should suggest GCA and lead to appropriate investigations [22]. The IHS classification criteria are informed by the literature, and will likely evolve as more is known about headache in GCA. Caution should be applied not to use criterion $2 \mathrm{~b}$ in isolation, for example many different types of headaches can improve with initiation of high dose GC treatment.

New onset headache is a cardinal symptom of GCA, with $67 \%$ reporting this symptom in the largest trial of GCA to date [23]. Headache alone may be the initial symptom for those with cranial GCA, and as the undiagnosed disease progresses, it becomes a more commonly reported symptom [24]. The full headache phenotype is little further described than "new onset" in the majority of the literature, and therefore when used in isolation, it appears to be only a modest discriminator when trying to predict the likelihood of GCA [25].

In a study from Japan, the headache has been reported as continuous in $60 \%$ of patients, with just under half having paroxysmal headache [26]. Case reports suggest that the headache is severe and unlike prior headaches in those who have had a prior history of headache [27]. However, there is a spectrum of severity of the pain, and the Japanese series has reported a range from severe (42\%), to moderate (37\%) and mild (21\%) headache [26].

The location of pain is commonly reported as being in the temporal artery (TA) region, when the TA is involved and may be more holocranial in nature in others, which probably reflects the arterial involvement of the disease [28]. Nineteen cases of GCA that were reviewed at the Japanese headache centre reported the location of the headache to be $60 \%$ temporal, $11 \%$ occipital, $11 \%$ frontal, $5 \%$ generalised. Of the remaining $15 \%$ no headache was recorded, one patient had isolated ear pain, and the other isolated jaw pain [26]. Importantly headache is also a common symptom at relapse [29].

\section{Recommendation}

The GCA headache phenotype is yet to be fully characterized in terms of frequency, severity and other associated characteristics. Vigilance is warranted in patients with new onset headache over the age of 50 years.

\section{What are the presenting features of GCA, apart from new onset headache?}

There is major overlap of symptoms between the three subtypes of GCA, namely: cranial GCA, LV-GCA and PMR. Cranial signs and symptoms include temporal cutaneous hyperalgesia, jaw or tongue claudication, abnormalities of the temporal artery on examination (prominent, beaded or irregular artery with a decreased pulse in up to one third of patients), scalp or tongue necrosis, tongue necrosis, and rarely stroke. Up to $30 \%$ develop ophthalmic signs and symptoms including transient monocular visual loss (amaurosis fugax) up to permanent loss of vision due to:

- Anterior ischaemic optic neuropathy

- Central retinal artery occlusion

- Branch retinal artery occlusion

- Posterior ischaemic optic neuropathy

- Choroidal infarction

Other visual symptoms include transient diplopia and persistent diplopia, secondary to extra-ocular muscle ischemia, isolated or multiple oculomotor cranial nerve palsies [4]. Systemic symptoms include fever, myalgia, fatigue, night sweats, loss of appetite, unintentional weight loss, and mood change [4]. Large vessel manifestations include aortitis, limb claudication (due to stenosis), thoracic and abdominal aneurysms.

\section{Recommendation}

A comprehensive history and examination in all those suspected with GCA will help guide investigations.

\section{What is the best way to diagnose GCA?}

Diagnosing GCA can be challenging and requires a full history for clinical features, thorough examination and a combination of investigations. There are classification criteria, but no universally accepted diagnostic criteria [30]. Choosing the optimal investigations depends on which area of the body the disease is suspected to be present because one third of LV-GCA patients have no ultrasonographic evidence of cranial/temporal arteritis [19], and more than half of LV-GCA patients have a normal temporal artery biopsy [31].

\section{Laboratory markers}

There is currently no specific blood biomarker that can definitely diagnose GCA. The majority of those with GCA have elevated acute phase reactants at disease 
onset such as an elevated erythrocyte sedimentation rate (ESR) [32] or plasma viscosity, C-reactive protein (CRP) [32] and platelets [33]. However inflammatory markers have been reported as normal in between 1 and $10 \%$ [32, 34]. Additionally, few cases who have presented with visual loss within the literature have reported normal inflammatory markers $[35,36]$. It is well known that those with cranial GCA typically have lower inflammatory markers than patients with extracranial manifestations (LV-GCA and PMR) [24, 37, 38]. Additionally, those with higher inflammatory markers tend to have fewer ischaemic events [39]. Other blood changes include anaemia and elevated liver enzymes.

\section{Recommendation}

A combination of full blood count, ESR (or plasma viscosity) and CRP should be performed in those with suspected GCA which may support the clinical diagnosis.

\section{Confirmatory investigational tests}

Both standard treatment with GC [40] and indeed licensed targeted treatment [41] for GCA confers significant risk of morbidity, therefore a confirmatory investigational test should be performed to secure the diagnosis.

\section{Recommendation}

A confirmatory investigational test should be performed where possible in all those with suspected GCA.

\section{Imaging - cranial GCA}

Colour Duplex Ultrasonography (CDUS) is a non-invasive imaging modality that assesses the arterial wall anatomy, the patency of the lumen and allows assessment of blood flow. In GCA, imaging the temporal arteries shows homogenous, hypoechogenic (dark), circumferential vessel wall thickening, which is known as the "halo sign" when pictured in cross-section (Fig. 1) [42]. On meta-analysis the sensitivity and specificity of a unilateral hypoechoic halo compared to positive $\mathrm{TAB}$ were respectively of $68 \%$ (95\% Confidence Intervals (CI): 57-78) and $81 \%$. The diagnostic value of any abnormality on CDUS, such as hypoechoic halo and/or stenosis and/or occlusion, compared to $\mathrm{TAB}$ had a sensitivity of $78 \%$ (95\% CI, 64-87), a specificity of $79 \%$ [43].

Other features on examination include the compression sign when using b-scan mode, where a normal artery image is extinguished on compression whilst an artery with features of active vasculitis is not, providing superior inter-observer agreement [44]. This is important in distinguishing patients with artefactual changes which lead to the detection of false halos (such as the presence of extensive vessel tortuosity and/or atherosclerosis) from a true halo.
Major advantages of CDUS are that it is non-invasive and can sample the majority of main arterial territories which can be affected such as the common superficial temporal artery, frontal and parietal branches as well as axillary, carotid, subclavian and vertebral arteries [45, 46]. The Temporal Artery Biopsy vs Ultrasound in Diagnosis of Giant Cell Arteritis (TABUL) study, a crosssectional prospective study of 381 patients investigated for GCA, has given the most comprehensive analysis of use of CDUS in GCA [45]; with this evidence CDUS has allowed for a significant reduction in the requirement for temporal artery biopsy [47].

${ }^{18} \mathrm{~F}$-fluorodeoxyglucose positron emission tomography $\left({ }^{18} \mathrm{~F}\right.$-FDG-PET) has traditionally been technically difficult to interpret in cranial disease due to the brain activity and the size of the temporal vessels being assessed. Recently the GAP study [48], reported on a progressive protocol to assess the head, neck and thorax with a dedicated time-of-flight 18F-FDG-PET protocol and $1 \mathrm{~mm}$ CT reconstruction. They found that it was helpful early in the investigational pathway not only to distinguish masquerades of GCA but also for distinguishing active disease in the intracranial vessels (Fig. 2). However, major disadvantages of this modality remain such as the cost, radiation exposure, availability and validation with existing imaging modalities.

\section{Recommendation}

Where CDUS is readily available, it should be used to confirm the clinical diagnosis of GCA.

\section{Temporal artery biopsy}

Temporal artery biopsy (TAB) allows for a histological diagnosis, but in some centres may be difficult to access readily and for the patient, it is an invasive procedure. When a TAB is positive it provides justification for treatments used in GCA, however when negative can create diagnostic uncertainty. The sensitivity of $T A B$ ranges in the literature between 80 and $90 \%$ probably due to publication bias, however in a comparative trial, it was shown to have a poor sensitivity of 39\% [45]. Negative biopsies can be a concern for the clinician, and a number of factors may contribute including the nature of the tissue obtained (i.e vein instead of artery biopsied), length of biopsy (preferably greater than $1 \mathrm{~cm}$ ), histological interpretation and length of time on GC treatment resulting in a false negative biopsy $[45,49]$. However, given the morbidity of treatment, some would still consider performing a biopsy at any point during the disease [50]. The utility of TAB has been recommended by some international bodies to be superseded by non-invasive imaging modalities such as CDUS [20]. Some centres have chosen to use TAB when the results 


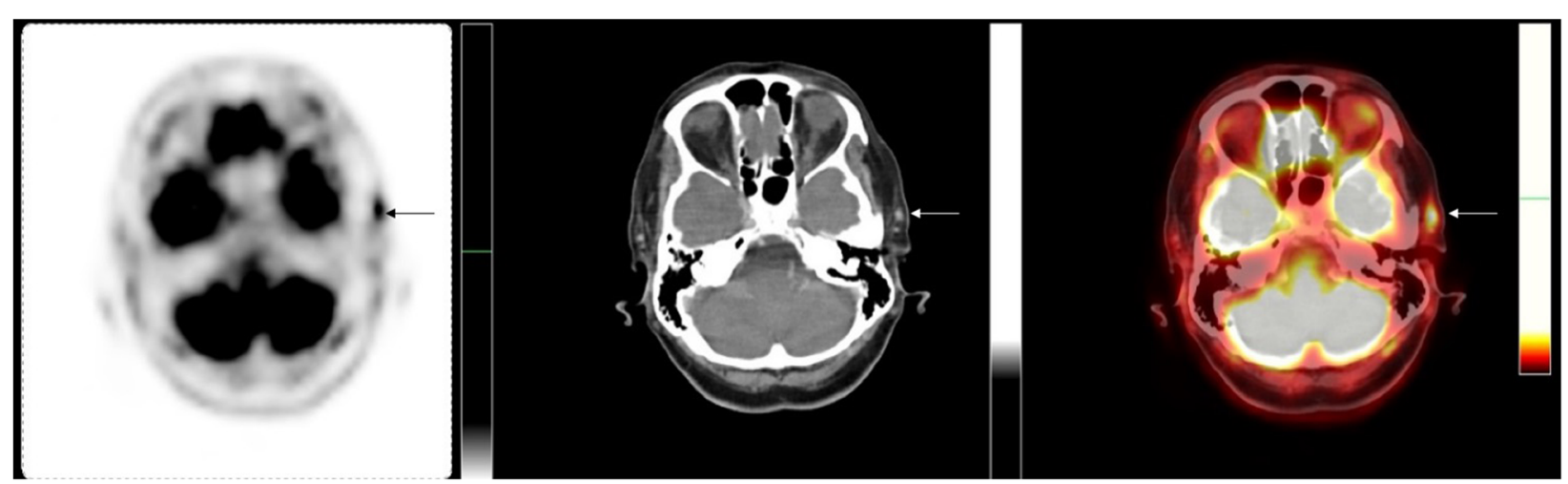

Fig. 2 Increased FDG uptake in the temporal arteries, more pronounced on the left. Images from left to right: FDG-PET, CT (soft window), and fusion

of CDUS are either equivocal or not in keeping with the clinical presentation [51].

\section{Recommendation}

Temporal artery biopsy remains a useful and specific investigation for a definitive diagnosis of GCA.

\section{Imaging - large vessel GCA (LV-GCA)}

LV-GCA often presents as an inflammatory syndrome and is only detected by imaging modalities such as: CDUS, computed tomography (CT) / CT angiography (CTA), magnetic resonance imaging/angiography (MRI/MRA) or ${ }^{18}$ F-FDG-PET. CDUS shows axillary and carotid artery circumferential homogenous hypoechogenic wall thickening, which is similar to the findings in the temporal arteries when affected [19]. However, CDUS lacks the ability to image the larger thoracic vessels.

${ }^{18} \mathrm{~F}$-FDG-PET is usually combined with low-dose CT and has a role in assessing disease activity and the extent of involvement in extracranial GCA (case vignette 1 and 2, Figs. 2, 3 and 4) [52]. GCA with a reported sensitivity of 77\% [53]. Increased FDG uptake in the vessel wall is the hall-mark of vasculitis in PET. In general, visual evidence of vascular uptake higher than tracer uptake in the liver is considered to be suspicious for LVV [54]. ${ }^{18}$ F-FDG-PET imaging can demonstrate involvement of the larger aortic vessels and increased reliability. Moreover, the increased uptake seems to persist longer after treatment initiation.

\section{Recommendation}

Where extra-cranial disease is suspected ${ }^{18} \mathrm{~F}$-FDG-PET/ CT should be performed.

Are there any other imaging modalities being utilised in GCA?

High-resolution (3 up to 7 Tesla) MRI to image the superficial and extracranial arteries in GCA demonstrated arterial

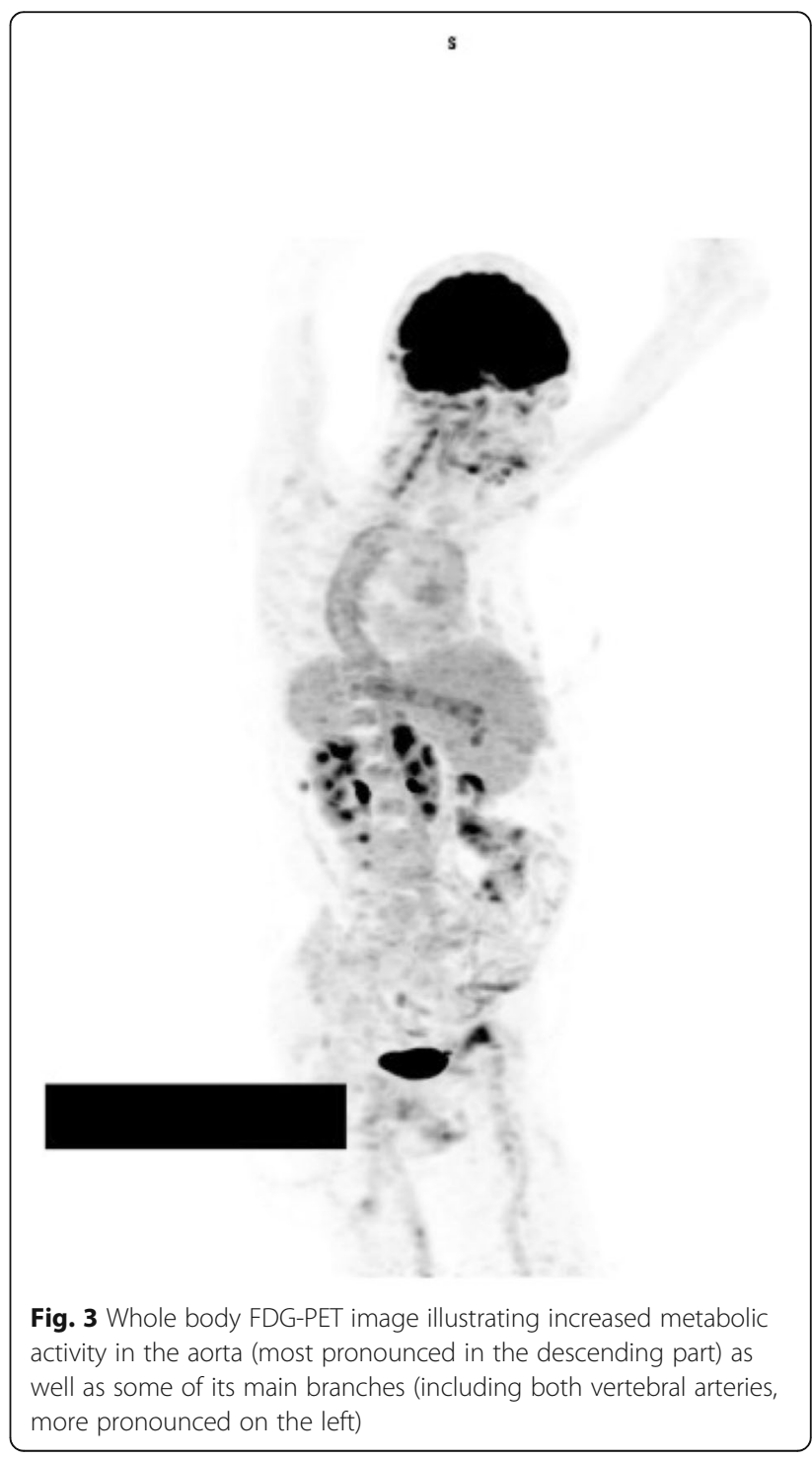




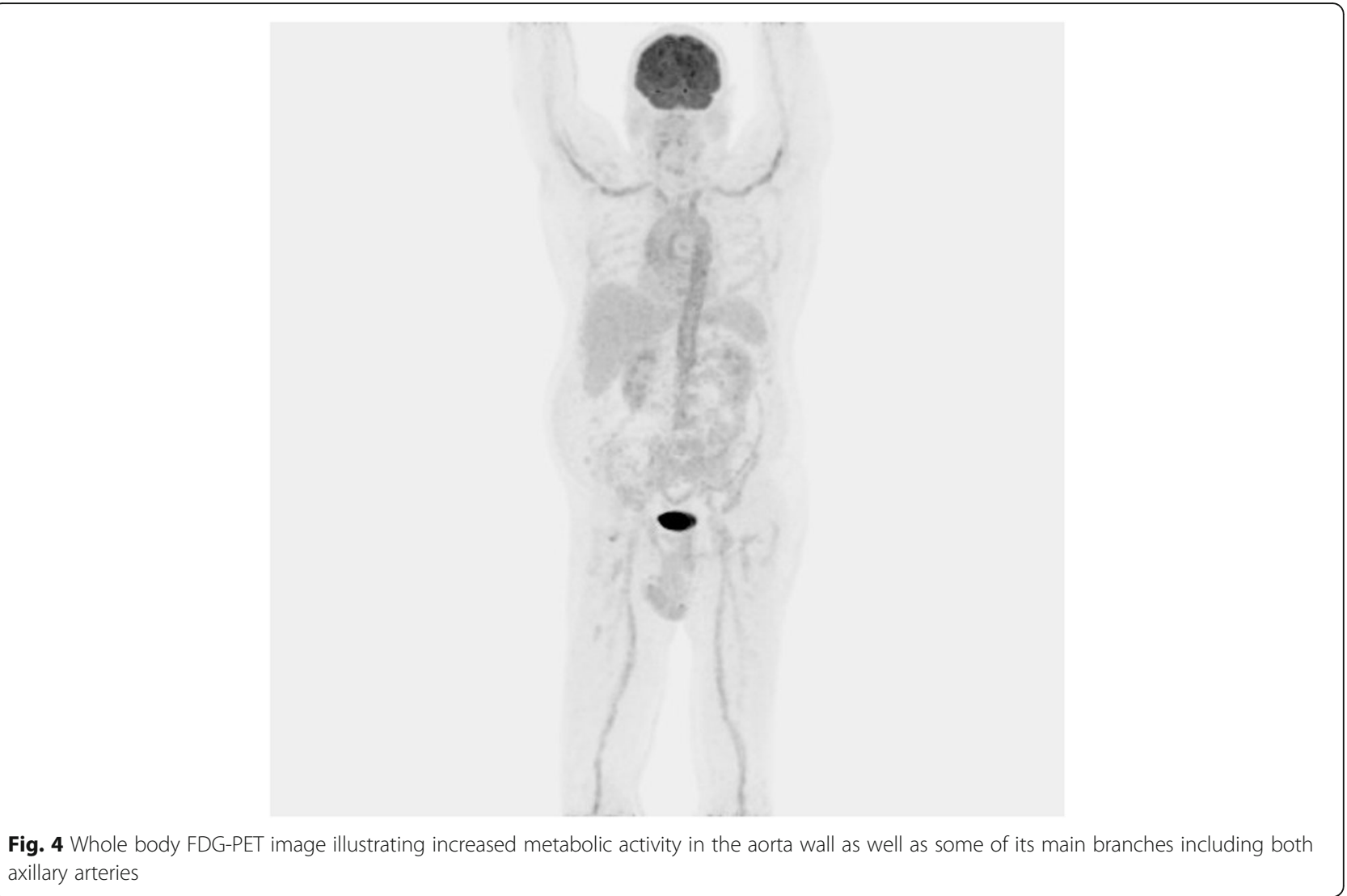

wall thickening with peri-adventitial and mural contrast enhancement with sensitivities ranging from 50 to $89 \%$ [55]. Other imaging techniques that are being investigated include photoacoustic imaging [56] and optical coherence tomography of the superficial temporal artery [57].

\section{What are the benefits of rapid access GCA diagnostic pathways?}

The mean diagnostic delay for those with cranial symptoms is 9 weeks and for those presenting without cranial symptoms is over 17 weeks. There are many factors leading to delay, including delayed presentation, low clinical suspicion, belated referral for specialist assessment, and lack of access to confirmatory diagnostic tests [15]. General public awareness of GCA is low and the early symptoms of GCA are non-specific. If GC are started, but there is a delay in performing a confirmatory investigational test then the potential for a secure diagnosis is reduced, because both CDUS and TAB are less likely to be positive with increasing time on high dose glucocorticoid therapy. The accuracy of biopsy was likely to be greatest if performed within 3 days of starting steroids (sensitivity $48 \%$ vs $33 \%$ for biopsies performed 7 or more days after commencing steroid treatment). For ultrasound, the accuracy was highest for patients seen on no more than one dose of steroids (sensitivity 64\%), but was still maintained at $47 \%$ up to 7 days after commencing high dose GC [45]. The literature shows improved patient outcomes for those who have rapid access pathways $[18,58]$ what is yet to be demonstrated is the economic benefit of these specialists centres.

\section{Recommendation}

- To reduce diagnostic delay, improve likelihood for securing diagnosis and improve patient outcomes, patients with suspected GCA should be referred to a rapid access specialist GCA service where available.

- Where ophthalmic symptoms are present, emergency referral to an ophthalmologist should be sought to confirm the nature of the visual symptoms.

\section{What is the treatment of GCA?}

What is the immediate treatment for GCA?

Where there is a high clinical suspicion of GCA immediate high dose GC should be started [59]. The standard initial GC dose for GCA is between 40 and $60 \mathrm{mg}$ oral prednisolone equivalent per day, depending on the patient characteristics, including pre-existing comorbidities and body weight. 
For those with cranial ischaemic symptoms (such as visual loss secondary to GCA or stroke) high dose intravenous methylprednisolone $500 \mathrm{mg}-1000 \mathrm{mg}$ induction therapy for 3 days may be used, followed by reducing course of oral glucocorticoids.

The little evidence in the literature to guide the route of administration of glucocorticoids is conflicting. Mazlumzadeh et al [60] found that a 3-day induction of IV methylprednisolone allowed a more rapid weaning from oral prednisone than placebo and conferred a reduced the cumulative glucocorticoid dose at Week 78 . However, Chevalet et al [61] showed no benefit for a single induction dose of IV methylprednisolone in reducing cumulative steroid dose at 1 year. Hayreh et al. [62] in his observational case series did not show any obvious benefit between IV or oral administration, although those treated with IV tended to have poorer visual acuity at diagnosis.

Worryingly, there is evidence that sight loss can still occur in nearly one third, despite the use of high dose IV methylprednisolone within the first 6 days [63].

\section{Recommendation}

High dose GC should be started immediately for those with a high index of clinical suspicion for GCA.

\section{What is the long-term GCA treatment?}

Data from the GiACTA trial [64] reported that only 14\% of patients on a short 6 month oral GC taper (without additional tocilizumab) achieved remission at 12 months, and $18 \%$ achieved remission at 12 months, if given a 12 month GC tapering regimen. The EULAR guidelines have recommended maintaining induction levels of 40-60 mg per day until there is clear resolution of symptoms and normalization of inflammatory markers. GC should be tapered to a target of $15-20 \mathrm{mg} /$ day within 2-3 months and then to $\leq 5 \mathrm{mg} /$ day after 1 year, with an aim to stop within $1-2$ years if there is no relapse; this strategy would result in a projected cumulative dose of just over $6 \mathrm{~g}$ [59].

\section{Recommendation}

GC are used for 6-24 months and should be tapered according to response.

\section{How are the side-effects of glucocorticoids mitigated?}

The prolonged use of GC is well documented and can exacerbate conditions such as hypertension, diabetes mellitus, heart failure, and osteoporosis. It can also cause depression [65]. In patients with GCA there is a high morbidity with $86 \%$ developing at least one side effect and $68 \%$ developing more than two [40]. Real world cumulative dose of GC can far exceed guideline recommendations, and one study showed a mean cumulative dose of $8.4 \mathrm{~g}$, with more than one third accumulating a dose greater than $10 \mathrm{~g}$ [66]. This is likely because disease relapses are common, reported to occur in half of all patients, necessitating an increase in GC, or a delay in tapering the dose [67]. For those with a history of relapse there is an increased prevalence of osteoporosis [68]. The adverse event hazard ratio is increased by approximately $3 \%$ for every $1000 \mathrm{mg}$ increase in the cumulative GC dose [69].

\section{Recommendation}

- Consider prescribing a proton pump inhibitor for gastrointestinal protection in people at risk of gastrointestinal bleeding or dyspepsia.

- Consider prescribing bone-sparing treatment, such as bisphosphonates, to people who are taking high doses of GC.

\section{Are conventional second line steroid sparing therapies effective in GCA?}

There have been three randomised, placebo-controlled trials investigating Methotrexate (MTX), between doses of 7.5-15 mg per week, as an adjunctive steroid-sparing agent [70-72] Despite methodological limitations of each individual study, a meta-analysis using pooled individual patient data from these trials demonstrated a reduced risk of first relapse (HR 0.65, 95\% CI 0.44 to 0.98 , $p=0.04$ ) and second relapse (HR $0.49,95 \%$ CI 0.27 to $0.89, p=0.02$ ), a higher probability of glucocorticoid-free remission for at least 24 weeks (HR 2.84, 95\% CI 1.52 to 5.28, $p<0.001)$ and a lower cumulative glucocorticoid dose $(0.84 \mathrm{~g}$ less glucocorticoid use after 48 weeks in patients treated with MTX versus placebo). There was no significant difference in side effects between the intervention and placebo groups. On further review of the included studies a low dose of MTX had been used, compared with current practice and the patient selection included those in whom steroid titration from low doses had failed on several occasions [73]. Dumont et al. [67] recently reported a significant reduction in the duration of glucocorticoid treatment in half of their cohort with glucocorticoid-dependent disease who had received a steroid sparing agent (mainly but not exclusively methotrexate) of 36 [15-115] versus 61 [14-212] months $(p=0.008)$.

Other conventionally used steroid sparing therapies such as Azathioprine [74] [De Silva 1986], Cyclophosphamide [75] and Mycophenolate [76] have not been shown to be superior to GC alone. Ciclosporin was been deemed ineffective [77]. Use of anti-tumour necrosis factor (TNF) alpha therapy in GCA was disappointing [78]. Leflunomide has been investigated in an open-label prospective single centre study of 76 patients and shown 
some benefit in controlling disease, reducing the use of GC [79].

\section{Recommendation}

Second line therapy with MTX should be considered in patients with GCA in order to maintain disease control and achieve glucocorticoid reduction, but the effectiveness of MTX is modest.

\section{What is the evidence for antiplatelet therapy in GCA?}

Aspirin is widely used to prevent ischaemic complications such as stroke and myocardial infarction in those with cardiovascular disease. The literature has conflicting reports of the protective use of aspirin in GCA, with some supporting its beneficial effects $[80,81]$ and others refuting it $[82,83]$. Currently overwhelming clinical evidence of a reduction in ischaemic events is lacking [84]. The use of low-dose aspirin as an adjunctive treatment in GCA must acknowledge the recognised haemorrhagic risks associated with aspirin and concurrent GC use.

\section{Recommendation}

Clinician discretion and patient preference on initiating aspirin therapy in GCA may be applied, unless patients have associated pre-existing comorbid conditions which justify its use.

\section{What is the evidence for use of biologics in GCA?}

Tocilizumab (TCZ), a humanised monoclonal antibody to the IL- 6 receptor, has been investigated in phase II [85] and phase III [64] RCTs. In the phase II study 30 patients with new-onset or relapsing disease were randomised to receive either weekly TCZ infusions or placebo, both with a tapering GC regimen. At week 12, $85 \%$ of the TCZ group had achieved clinical and biochemical remission as compared with only $40 \%$ of those in the placebo group $(p=0.03)$. At 1 year, $85 \%$ of the TCZ group had remained relapse-free versus a mere $20 \%$ of the placebo group $(p=0.001)$ Use of TCZ resulted in a significant reduction in steroid requirement [86].

The Giant Cell Arteritis Actemra (GiACTA) trial was a large phase III, multi-centre, double-blind, placebocontrolled study examining the efficacy of subcutaneously administered TCZ to induce and sustain remission to 12 months. GiACTA included newly diagnosed patients with GCA and those with refractory disease. Patients were enrolled and randomised to one of four arms; weekly or fortnightly TCZ (162 mg) combined with a 26-week prednisolone taper or; placebo plus a 26week or 52-week prednisolone taper. At 12 months, those receiving TCZ were significantly more likely to have achieved sustained remission as compared with both the 26-week and 52-week steroid taper groups. This confirmed a significant steroid-sparing effect of
TCZ (patients receiving TCZ had required half the cumulative glucocorticoid dose used in the placebo groups) [64].

The side effect profile of TCZ (Table 1) is well documented in the rheumatoid arthritis literature [40]. Within the older GCA population concern has been raised regarding the risk of concurrent diverticular disease, transient neutropenias, and elevations of triglycerides and deranged liver function tests [87].

The cost, side effect profile and inability to serially monitor the serum CRP for evidence of relapse means that there is a reluctance to prescribe TCZ for new onset patients, despite the trial evidence. However, when patients are deemed refractory i.e. those people with GCA who never achieve remission, this is typically a more accepted use of TCZ. Likewise, for those patients with glucocorticoid-induced side effects or patients with significant pre-existing comorbidities such as psychiatric disturbances, pancreatitis, or uncontrolled diabetes or hypertension, tocilizumab could be effective as a first line treatment $[21,59]$.

The 2-year open-label extension study from GiACTA analysed 215 of the original 251 randomised patients. Participants in clinical remission received no further treatment and those not in clinical remission received weekly TCZ (162 mg) and/or GC and/or MTX. Higher proportions of those originally assigned to weekly TCZ were treatment-free compared with those originally assigned to placebo. Importantly, the cumulative dose of GC was substantially lower (almost half) in patients assigned to weekly TCZ $(2604 \mathrm{mg})$ versus patients given

Table 1 Side effect profile for Tocilizumab [41]

\begin{tabular}{|c|c|}
\hline Frequency & Side effect \\
\hline Common & $\begin{array}{l}\text { - abdominal pain } \\
\text { - conjunctivitis } \\
\text { - cough } \\
\text { - dizziness } \\
\text { - dyslipidaemia } \\
\text { - dyspnea } \\
\text { - gastrointestinal disorders } \\
\text { - headache } \\
\text { - hypersensitivity } \\
\text { - hypertension } \\
\text { - increased risk of infection } \\
\text { - leucopenia } \\
\text { - neutropenia } \\
\text { - oral ulcers } \\
\text { - peripheral oedema } \\
\text { - skin reactions } \\
\text { - weight increases }\end{array}$ \\
\hline Rare & $\begin{array}{l}\text { - hypothyroidism } \\
\text { - nephrolithiasis }\end{array}$ \\
\hline Very rare & $\begin{array}{l}\text { - infusion related reaction } \\
\text { - interstitial lung disease } \\
\text { - pancytopenia } \\
\text { - Stevens-Johnson syndrome }\end{array}$ \\
\hline
\end{tabular}


either 26 weeks of GC plus placebo $(5006 \mathrm{mg}$ ) or 52 weeks of GC plus placebo $(5322.5 \mathrm{mg})$. Interestingly, patients assigned to placebo plus only 26 weeks of GC required almost as much GC therapy as those assigned to 52 weeks of GC plus placebo, reflecting the poor control of disease when using 26 weeks of GC monotherapy [86].

\section{Recommendation}

Use of TCZ should be considered for patients with a confirmed diagnosis of GCA (based on imaging or TAB) who have either refractory disease, or those with comorbid disease that could be significantly exacerbated by GC use.

\section{Conclusions}

There have been significant advances occurring to routine clinical GCA care. Guideline bodies from Europe have updated their recommendations to rheumatologists $[20,59,88]$ and neurologists need to be up to date to ensure optimal evidence-based practice for their patients.

This EHF guidance serves to inform neurologists who may be consulted regarding a patient with a new onset headache over the age of 50 years old, and who indeed may manage patients with GCA long-term. With advances in imaging and treatment it is no longer recommended to diagnose GCA on clinical grounds alone. A confirmatory investigational test such as CDUS or TAB is required, because the disease course of an individual currently cannot be readily predicted at diagnosis and escalation in therapy may be needed, but eligibility for escalation therapy is likely to require prior evidence of a definitive diagnosis.

An appreciation of the growing evidence regarding glucocorticoid morbidity is required in this population. Randomized clinical trials have shown that traditional steroid sparing agents perform only modestly; by contrast, biologic agents such as TCZ have clinically relevant efficacy in GCA. As other future targeted therapies are on the horizon (Table 2), and as our understanding

Table 2 Drugs currently being investigated for treatment of GCA

\begin{tabular}{|c|c|}
\hline Drug name & Mechanism of action \\
\hline Abatacept & $\begin{array}{l}\text { Humanized fusion protein that modifies co-stimulation in } \\
\text { antigen presentation, inhibiting T-cell activity }\end{array}$ \\
\hline Anakinra & Monoclonal antibody to the $\mathrm{IL}-1 \beta$ receptor \\
\hline Baricitinib & $\begin{array}{l}\text { Synthetic DMARD, which targets the intracellular pro- } \\
\text { inflammatory Janus kinase (JAK) family of enzymes }\end{array}$ \\
\hline Gevokizumab & $\begin{array}{l}\text { Recombinant monoclonal antibody to IL-1 } \beta \text {, a pro- } \\
\text { inflammatory cytokine }\end{array}$ \\
\hline Rituximab & $\begin{array}{l}\text { Chimeric monoclonal antibody against the protein CD20, } \\
\text { which is primarily found on the surface of immune } \\
\text { system B cells }\end{array}$ \\
\hline
\end{tabular}

of the disease entity becomes more informed this guidance will require timely updating.

\section{Supplementary information}

Supplementary information accompanies this paper at https://doi.org/10. 1186/s10194-020-01093-7.

Additional file 1: Movie S1. Whole body FDG-PET movie illustrating increased metabolic activity in the aorta (most pronounced in the descending part) as well as some of its main branches (including both vertebral arteries, more pronounced on the left).

Additional file 2: Case Vignette 1. the overlap of LV-GCA, cranial GCA and PMR. Case Vignette 2: Utility of FDG PET imaging to diagnose GCA.

\section{Abbreviations}

CDUS: Colour Duplex Ultrasonography; CRP: C-reactive protein;

CT: Computed tomography; CTA: Computed tomography angiography; DMARDs: Disease modifying anti-rheumatic drugs; EHF: European Headache Federation; ESR: Erythrocyte sedimentation rate; FDG: Fluorodeoxyglucose; GiACTA: The Giant Cell Arteritis Actemra Trial; GCA: Giant cell arteritis; IHS: International Headache Society; MRI: Magnetic resonance imaging; MXT: Methotrexate; PET: Positron emission tomography; PMR: Polymyalgia rheumatica; RCT: Randomised controlled trial; TAB: Temporal artery biopsy; TCZ: Tocilizumab; TNF: Tumour necrosis factor

\section{Acknowledgements}

We thank Professor Ingeborg Goethals and Mr. Sam Donche of the Department of Nuclear Medicine of the Ghent University Hospital for providing the images and video illustrating the case vignette.

\section{Authors' contributions}

SPM performed the literature review, interpretation, conceptualized and designed the statement and drafted and reviewed the manuscript. RL interpretation of the literature and critical review of the manuscript. KP and $\mathrm{J}$ sourced case data and performed a critical review of the manuscript. AS performed critical review of manuscript. The final version has been reviewed and approved by all authors. KP and AS are or were Members of Council of the European Headache Federation.

\section{Funding}

No funds were used in the preparation of this manuscript. AS is funded by an NIHR Clinician Scientist Fellowship (NIHR-CS-011-028) and by the Medical Research Council, UK (MR/K015184/1).

\section{Availability of data and materials}

All data generated or analysed during this study are included in this published article and its supplementary information files.

Ethics approval and consent to participate Not applicable.

\section{Consent for publication}

Not applicable.

\section{Competing interests}

SPM - advisory board and speaker fees for Roche; speaker fees for Chugairoche Ltd.

$\mathrm{KP}$ - none relating to the manuscript.

$\mathrm{JV}$ - none relating to the manuscript

$\mathrm{RL}$ - advisory board and speaker fees for Roche; speaker fees for AbbVie,

Chugai-Roche Ltd.; grants from Celgene, Roche, Vifor.

AS - speaker fees for Roche.

\section{Author details}

${ }^{1}$ Birmingham Neuro-Ophthalmology, University Hospitals Birmingham NHS Foundation Trust, Queen Elizabeth Hospital, Birmingham, UK. ²Department of Neurology, Ghent University Hospital, Ghent, Belgium. ${ }^{3}$ Department of Neurology, Vrije Universiteit Brussel (VUB), Universitair Ziekenhuis Brussel (UZ Brussel), Brussels, Belgium. ${ }^{4}$ The Nuffield Department of Orthopaedics, 
Rheumatology and Musculoskeletal Sciences, Kennedy Institute of Rheumatology, Roosevelt Drive, Headington, Oxford OX3 7FY, UK. ${ }^{5}$ Metabolic Neurology, Institute of Metabolism and Systems Research, University of Birmingham, Edgbaston, Birmingham B15 2TT, UK. ${ }^{6}$ Department of Neurology, University Hospitals Birmingham, Queen Elizabeth Hospital, Birmingham, UK. ${ }^{7}$ Centre for Endocrinology, Diabetes and Metabolism, Birmingham Health Partners, Birmingham, UK.

Received: 16 September 2019 Accepted: 6 March 2020

Published online: 17 March 2020

\section{References}

1. Dejaco C, Brouwer E, Mason JC, Buttgereit F, Matteson EL, Dasgupta B (2017) Giant cell arteritis and polymyalgia: current challenges and opportunities. Nat Rev Rheumatol 13(10):578-592

2. Jennette JC, Falk RJ, Bacon PA et al (2013) 2012 revised international Chapel Hill consensus conference nomenclature of Vasculitides. Arthritis Rheum 65(1):1-11

3. Borchers AT, Gershwin ME (2012) Giant cell arteritis: a review of classification, pathophysiology, geoepidemiology and treatment. Autoimmun Rev 11(6-7):A544-A554

4. Al-Mousawi AZ, Gurney SP, Lorenzi AR, Pohl U, Dayan M, Mollan SP (2019) Reviewing the pathophysiology behind the advances in the Management of Giant Cell Arteritis. Ophthalmol Ther 8(2):177-193

5. Carmona FD, Coit P, Saruhan-Direskeneli G, Hernández-Rodríguez J, Cid MC, Solans R et al (2017) Analysis of the common genetic component of largevessel vasculitides through a meta-Immunochip strategy. Sci Rep 7:43953. https://doi.org/10.1038/srep46012

6. Mackie SL, Taylor JC, Haroon-Rashid L et al (2015) Association of HLA-DRB1 amino acid residues with giant cell arteritis: genetic association study, metaanalysis and geo-epidemiological investigation. Arthritis Res Ther 17(1):195

7. Chandran AK, Udayakumar PD, Crowson C et al (2015) The incidence of Giant cell arteritis in Olmsted County Minnesota, over a sixty year period 1950 - 2009. Scand J Rheumatol 44(3):215-218

8. Crowson CS, Matteson EL, Myasoedova E et al (2011) The lifetime risk of adult-onset rheumatoid arthritis and other inflammatory autoimmune rheumatic diseases. Arthritis Rheum 63:633-639

9. Brekke LK, Brekke LK, Diamantopoulos AP, Fevang BT, Aßmus J, Esperø E, Gjesdal CG (2017) Incidence of giant cell arteritis in Western Norway 1972 2012: a retrospective cohort study. Arthritis Res Ther 19(1):278 [published correction appears in Arthritis Res Ther. 2018 Dec 7;20(1):271]

10. Yates M, Macgregor AJ, Robson J, Craven A, Merkel PA, Luqmani RA, Watts RA (2017) The association of vascular risk factors with visual loss in giant cell arteritis. Rheumatology (Oxford) 56(4):524-528

11. Czihal M, Tschaidse J, Bernau C, Lottspeich C, Köhler A, Dechant C, SchulzeKoops H, Hoffmann U, Mackert MJ, Thurau S (2019) Ocular ischaemic complications in giant cell arteritis: CHADS2-score predicts risk of permanent visual impairment. Clin Exp Rheumatol 37(Suppl 117(2)):61-64

12. Caselli RJ, Hunder GG (1994) Neurologic complications of giant cell (temporal) arteritis. Semin Neurol 14:349-353

13. Ponte C, Rodrigues AF, O'Neill L, Luqmani RA (2015) Giant cell arteritis: current treatment and management. World J Clin Cases 3(6):484-494

14. Gonzalez-Gay MA, Vazquez-Rodriguez TR, Gomez-Acebo I et al (2009) Strokes at time of disease diagnosis in a series of 287 patients with biopsyproven giant cell arteritis. Medicine (Baltimore) 88:227-235

15. Prior JA, Ranjbar H, Belcher J, Mackie SL, Helliwell T (2017) Diagnostic delay for giant cell arteritis - a systematic review and meta-analysis. BMC Med 15:120

16. Helliwell T, Muller S, Hider SL, Prior JA, Richardson JC, Mallen CD (2018) Challenges of diagnosis and management of giant cell arteritis in general practice: a multimethods study. BMJ Open 8(2):e019320 Published 2018 Feb 3

17. Mollan SP, Begaj I, Mackie S et al (2015) Increase in admissions related to giant cell arteritis and polymyalgia rheumatica in the UK, 2002-13, without a decrease in associated sight loss: potential implications for service provision. Rheumatology (Oxford) 54(2):375-377

18. Patil P, Williams M, Maw WW, Achilleos K, Elsideeg S, Dejaco C et al (2015) Fast track pathway reduces sight loss in giant cell arteritis: results of a longitudinal observational cohort study. Clin Exp Rheumatol 33(2 Suppl 89): S-103-S-106

19. Schmidt WA, Seifert A, Gromnica-Ihle E, Krause A, Natusch A (2008) Ultrasound of proximal upper extremity arteries to increase the diagnostic yield in large-vessel giant cell arteritis. Rheumatology (Oxford) 47(1):96-101
20. Dejaco C, Ramiro S, Duftner C et al (2018 May) EULAR recommendations for the use of imaging in large vessel vasculitis in clinical practice. Ann Rheum Dis 77(5):636-643

21. Coath F, Gillbert K, Griffiths B et al (2018) Giant cell arteritis: new concepts, treatments and the unmet need that remains. Rheumatology (Oxford). https://doi.org/10.1093/rheumatology/key326

22. Headache Classification Committee of the International Headache Society (2018) The international classification of headache disorders, 3rd edition. Cephalalgia 38(1):1-211

23. Tuckwell K, Collinson N, Dimonaco S, Klearman M, Blockmans D, Brouwer E et al (2017) Newly diagnosed vs. relapsing giant cell arteritis: baseline data from the GiACTA trial. Semin Arthritis Rheum 46(5):657-664

24. Sun F, Ma S, Zheng W, Tian X, Zeng X (2016) A retrospective study of Chinese patients with Giant cell arteritis (GCA): clinical features and factors associated with severe ischemic manifestations. Medicine (Baltimore) 95(13): e3213

25. Ing EB, Miller NR, Nguyen A et al (2019) Neural network and logistic regression diagnostic prediction models for giant cell arteritis: development and validation. Clin Ophthalmol 13:421-430

26. Imai N, Kuroda R, Konishi T, Serizawa M, Kobari M (2011) Giant cell arteritis: clinical features of patients visiting a headache Clinic in Japan. Intern Med 50(16):1679-1682

27. Jones RV (1977) Unbearable headache of temporal arteritis. Br Med J $1(6072): 1355$

28. Manzo C (2016) Widespread headache as the first clinical manifestation of giant cell arteritis in patients affected by polymyalgia rheumatica. Reumatologia 54(5):236-238

29. Kermani TA, Warrington KJ, Cuthbertson D et al (2015) Disease relapses among patients with Giant cell arteritis: a prospective, longitudinal cohort study. J Rheumatol 42(7):1213-1217

30. Seeliger B, Sznajd J, Robson JC et al (2017) Are the 1990 American College of Rheumatology vasculitis classification criteria still valid? Rheumatology (Oxford) 56(7):1154-1161

31. Muratore F, Kermani TA, Crowson CS, Green AB, Salvarani C, Matteson EL et al (2015) Large-vessel giant cell arteritis: a cohort study. Rheumatology (Oxford) 54(3):463-470

32. Kermani TA, Schmidt J, Crowson CS et al (2011) Utility of erythrocyte sedimentation rate and $\mathrm{C}$-reactive protein for the diagnosis of giant cell arteritis. Semin Arthritis Rheum 41(6):866-871

33. Foroozan R, Danesh-Meyer H, Savino PJ, Gamble G, Mekari-Sabbagh ON, Sergott RC. (2002) Thrombocytosis in patients with biopsy-proven giant cell arteritis. Ophthalmology 109(7):1267-71.

34. Parikh M, Miller NR, Lee AG, Savino PJ, Vacarezza MN, Cornblath $W$ et al (2006) Prevalence of a normal C-reactive protein with an elevated erythrocyte sedimentation rate in biopsy-proven giant cell arteritis. Ophthalmology 113(10):1842-1845

35. Yu-Wai-Man P, Dayan MR (2007) Acta Ophthalmol Scand 85(4):460

36. Poole TR, Graham EM, Lucas SB (2003) Giant cell arteritis with a normal ESR and CRP. Eye 17:92-93

37. Gonzalez-Gay MA, Barros S, Lopez-Diaz MJ et al (2005) Giant cell arteritis: disease patterns of clinical presentation in a series of 240 patients. Medicine (Baltimore) 84:269-276

38. Salvarani C, Della BC, Cimino L et al (2009) Risk factors for severe cranial ischaemic events in an Italian population-based cohort of patients with giant cell arteritis. Rheumatology (Oxford) 48:250-253

39. Cid MC, Font C, Oristrell J et al (1998) Association between strong inflammatory response and low risk of developing visual loss and other cranial ischemic complications in giant cell (temporal) arteritis. Arthritis Rheum 41:26-32

40. Proven A, Gabriel SE, Orces C, O'Fallon WM, Hunder GG (2003) Glucocorticoid therapy in giant cell arteritis: duration and adverse outcomes. Arthritis Rheum 49:703-708

41. Mollan SP, Horsburgh J, Dasgupta B (2018) Profile of tocilizumab and its potential in the treatment of giant cell arteritis. Eye Brain 10:1-11

42. Cambron M (2011) De Raedt, Versijpt J, Geers C, Brouns R. a halo may lead the way. Cephalalgia 31(8):971-972

43. Rinagel M, Chatelus E, Jousse-Joulin S et al (2019) Diagnostic performance of temporal artery ultrasound for the diagnosis of giant cell arteritis: asystematic review and meta-analysis of the literature. Autoimmun Rev 18:56-61

44. Aschwanden M, Imfeld S, Staub D, Baldi T, Walker UA, Berger CT et al (2015) The ultrasound compression sign to diagnose temporal giant cell arteritis 
shows an excellent interobserver agreement. Clin Exp Rheumatol 33:S-113S-115

45. Luqmani R, Lee E, Singh $S$ et al (2016) The role of ultrasound compared to biopsy of temporal arteries in the diagnosis and treatment of Giant cell arteritis (TABUL): a diagnostic accuracy and cost-effectiveness study. Health Technol Assess 20(90):1-238

46. Monti S, Floris A, Ponte $C$ et al (2018) The use of ultrasound to assess giant cell arteritis: review of the current evidence and practical guide for the rheumatologist. Rheumatology (Oxford) 57(2):227-235

47. Monti S, Floris A, Ponte C et al (2018) The proposed role of ultrasound in the management of giant cell arteritis in routine clinical practice. Rheumatology 57:112-119

48. Sammel AM, Hsiao E, Schembri G et al (2019) Diagnostic accuracy of PET/CT scan of the head, neck and chest for Giant cell arteritis: the double-blinded Giant cell arteritis and PET scan (GAPS) study. Arthritis Rheumatol. https:// doi.org/10.1002/art.40864

49. Achkar AA, Lie JT, Hunder GG, O'Fallon WM, Gabriel SE (1994) How does previous corticosteroid treatment affect the biopsy findings in giant cell (temporal) arteritis? Ann Intern Med 120(12):987-992

50. Guevara RA, Newman NJ, Grossniklaus HE (1998) Positive temporal artery biopsy 6 months after prednisone treatment. Arch Ophthalmol 116(9):1252-1253

51. Croft A, Thompson N, Duddy M et al (2015) Cranial ultrasound for the diagnosis of giant cell arteritis. A retrospective cohort study. J R Coll Physicians Edinb 45(4):268-272

52. Slart RHJA (2018) Writing group; reviewer group; FDG-PET/CT(a) imaging in large vessel vasculitis and polymyalgia rheumatica: joint procedural recommendation of the EANM, SNMMI, and the PET interest group (PIG), and endorsed by the ASNC. Eur J Nucl Med Mol Imaging 45(7):1250-1269

53. Blockmans D (2003) The use of (18F) fluorodeoxyglucose positron emission tomography in the assessment of large vessel vasculitis. Clin Exp Rheumatol 21(6 Suppl 32):S15-S22

54. Stellingwerff MD, Brouwer E, Lensen KJ, Rutgers A, Arends S, van der Geest KS et al (2015) Different scoring methods of FDG PET/CT in Giant cell arteritis: need for standardization. Medicine (Baltimore) 94(37):e1542

55. Klink T, Geiger J, Both M et al (2014) Giant cell arteritis: diagnostic accuracy of MR imaging of superficial cranial arteries in initial diagnosis-results from a multicenter trial. Radiology 273(3):844-852

56. Sheikh R, Cinthio M, Dahlstrand U, Erlov T, Naumovska M, Hammar B, Zackrisson S, Jansson T, Reistad N, Malmsjo M (2019) Clinical translation of a novel photoacoustic imaging system for examining the temporal artery. IEEE Trans Ultrason Ferroelectr Freq Control 66:472-480

57. Mollan S, Keane P, Denniston A (2017) The use of transdermal optical coherence tomography to image the superficial temporal arteries. Eye 31(1): 157-160

58. Diamantopoulos AP, Haugeberg G, Lindland A, Myklebust G (2016) The fasttrack ultrasound clinic for early diagnosis of giant cell arteritis significantly reduces permanent visual impairment: towards a more effective strategy to improve clinical outcome in giant cell arteritis? Rheumatology (Oxford) 55(1):66-70

59. Hellmich B, Agueda A, Monti S, Buttgereit F, de Boysson H, Brouwer E et al (2020) 2018 Update of the EULAR recommendations for the management of large vessel vasculitis. Ann Rheum Dis 79(1):19-30.

60. Mazlumzadeh M, Hunder GG, Easley KA, Calamia KT, Matteson EL, Griffing WL, Younge BR, Weyand CM, Goronzy JJ (2006) Treatment of giant cell arteritis using induction therapy with high-dose glucocorticoids: a doubleblind, placebo-controlled, randomized prospective clinical trial. Arthritis Rheum 54(10):3310-3318

61. Chevalet P, Barrier JH, Pottier P, Magadur-Joly G, Pottier MA, Hamidou M, Planchon B, El Kouri D, Connan L, Dupond JL, De Wazieres B, Dien G, Duhamel E, Grosbois B, Jego P, La Strat A, Capedeville J, Letellier P, Agron $L$ (2000) A randomized, multicenter, controlled trial using intravenous pulses of methylprednisolone in the initial treatment of simple forms of giant cell arteritis:a one year followup study of 164 patients. J Rheumatol 27:1484-1491

62. Hayreh SS, Zimmerman B (2003) Management of giant cell arteritis: our 27year clinical study; new light on old controversies. Ophthalmologica 217 239-259

63. Danesh-Meyer HV, Savino PJ, Gamble GG (2005) Poor prognosis of visual outcome after visual loss from giant cell arteritis. Ophthalmology 112:1098-1103

64. Stone JH, Tuckwell K, Dimonaco S et al (2017) Trial of tocilizumab in Giantcell arteritis. N Engl J Med 377(4):317-328
65. NICE Clinical knowledge summaries. Scenario: Corticosteroids: covers the management of people receiving oral corticosteroids in primary care. https:/ cks.nice.org.uk/corticosteroids-oral\#!lscenario. Last accessed 9 July 2019

66. Petri H, Nevitt A, Sarsour K, Napalkov P, Collinson N (2015) Incidence of giant cell arteritis and characteristics of patients: data-driven analysis of comorbidities. Arthritis Care Res 67:390-395

67. Dumont A, Parienti JJ, Delmas C, Boutemy J, Maigné G, Silva NM et al. (2020) Factors Associated with Relapse and Dependence on Glucocorticoids in Giant Cell Arteritis. J Rheumatol 47(1):108-116.

68. Alba MA, Garcia-Martinez A, Prieto-Gonzalez S et al (2014) Relapses in patients with giant cell arteritis: prevalence, characteristics, and associated clinical findings in a longitudinally followed cohort of 106 patients. Medicine (Baltimore) 93(5):194-201

69. Broder MS, Sarsour K, Chang E, Collinson N, Tuckwell K, Napalkov P et al (2016) Corticosteroid-related adverse events in patients with giant cell arteritis: a claims-based analysis. Semin Arthritis Rheum 46(2):246-252

70. Jover JA, Hernandez-Garcia C, Morado IC, Vargas E, Banares A, FernandezGutierrez B (2001) Combined treatment of giant-cell arteritis with methotrexate and prednisone. A randomized, double-blind, placebocontrolled trial. Ann Intern Med 134:106-114

71. Hoffman GS, Cid MC, Hellmann DB, Guillevin L, Stone JH, Schousboe J et al (2002) A multicenter, randomized, double-blind, placebo-controlled trial of adjuvant methotrexate treatment for giant cell arteritis. Arthritis Rheum 46: 1309-1318

72. Spiera RF, Mitnick HJ, Kupersmith M, Richmond M, Spiera H, Peterson MG et al (2001) A prospective, double-blind, randomized, placebo-controlled trial of methotrexate in the treatment of giant cell arteritis (GCA). Clin Exp Rheumatol 19:495-501

73. Mahr AD (2007) Over JA, Spiera RF, Hernández-García C, FernándezGutiérrez B, Lavalley MP, Merkel PA. Adjunctive methotrexate for treatment of giant cell arteritis: an individual patient data meta-analysis. Arthritis Rheum 56:2789-2797

74. De Silva M, Hazleman BL (1986) Azathioprine in giant cell arteritis/polymyalgia rheumatica: a double-blind study. Ann Rheum Dis 45(2):136-138

75. Quartuccio L, Maset M, De Maglio G, Pontarini E, Fabris M, Mansutti E et al (2012) Role of oral cyclophosphamide in the treatment of giant cell arteritis. Rheumatology (Oxford) 51(9):1677-1686

76. Sciascia S, Piras D, Baldovino S, Russo A, Naretto C, Rossi D et al (2012) Mycophenolate mofetil as steroid-sparing treatment for elderly patients with giant cell arteritis: report of three cases. Aging Clin Exp Res 24(3):273-277

77. Schaufelberger C, Andersson R, Nordborg E (1998) No additive effect of cyclosporin a compared with glucocorticoid treatment alone in giant cell arteritis: results of an open, controlled, randomized study. Rheumatology 37: 464-465

78. Samson M, Audia S, Janikashvili N, Bonnotte B (2014) Is TNF-alpha really involved in giant cell arteritis pathogenesis? Ann Rheum Dis 73:e1

79. Hočevar A, Ješe R, Rotar Ž, Tomšič M (2019) Does leflunomide have a role in giant cell arteritis? An open-label study. Clin Rheumatol 38(2):291-296

80. Nesher G, Berkun Y, Mates M, Baras M, Rubinow A, Sonnenblick M (2004) Low-dose aspirin and prevention of cranial ischemic complications in giant cell arteritis. Arthritis Rheum 50(4):1332-1337

81. Lee MS, Smith SD, Galor A, Hoffman GS (2006) Antiplatelet and anticoagulant therapy in patients with giant cell arteritis. Arthritis Rheum 54(10):3306-3309

82. Narvaez J, Bernad B, Gomez-Vaquero C, Garcia-Gomez C, Roig-Vilaseca D, Juanola X et al (2008) Impact of antiplatelet therapy in the development of severe ischemic complications and in the outcome of patients with giant cell arteritis. Clin Exp Rheumatol 26:S57-S62

83. Berger CT, Wolbers M, Meyer P, Daikeler T, Hess C (2009) High incidence of severe ischaemic complications in patients with giant cell arteritis irrespective of platelet count and size, and platelet inhibition. Rheumatology (Oxford) 48(3):258-261

84. Mollan SP, Sharrack N, Burdon MA, Denniston AK (2014) Aspirin as adjunctive treatment for giant cell arteritis. Cochrane Database Syst Rev 8:Cd010453

85. Villiger PM, Adler S, Kuchen S et al (2016) Tocilizumab for induction and maintenance of remission in giant cell arteritis: a phase 2, randomised, double-blind, placebo-controlled trial. Lancet 387(10031):1921-1927

86. Stone JH, Bao M, Han J, Aringer M, Blockmans D, Brouwer E, et al. Longterm outcome of tocilizumab for patients with Giant Cell Arteritis: results from part 2 of the GiACTA Tiral. EULAR $13^{\text {th }}$ June 2019: Oral Presentation \# OP0140 
87. Jobanputra P, Ford M (2017) Tocilizumab, an interleukin-6 inhibitor: a steroid sparing agent in giant cell arteritis. J R Coll Physicians Edinb 47(3): 250-252

88. Mackie SL, Dejaco C, Appenzeller S et al (2020) British Society for

Rheumatology guideline on diagnosis and treatment of giant cell arteritis. Rheumatology (Oxford) 59(3):e1-e23

\section{Publisher's Note}

Springer Nature remains neutral with regard to jurisdictional claims in published maps and institutional affiliations.

Ready to submit your research? Choose BMC and benefit from:

- fast, convenient online submission

- thorough peer review by experienced researchers in your field

- rapid publication on acceptance

- support for research data, including large and complex data types

- gold Open Access which fosters wider collaboration and increased citations

- maximum visibility for your research: over $100 \mathrm{M}$ website views per year

At BMC, research is always in progress.

Learn more biomedcentral.com/submissions 